\title{
Impact of Distance on Mode of Active Commuting in Chilean Children and Adolescents
}

\author{
Fernando Rodríguez-Rodríguez ${ }^{1, *}$ (i) , Carlos Cristi-Montero ${ }^{1}$, Carlos Celis-Morales ${ }^{2,3}$ (i) , \\ Danica Escobar-Gómez ${ }^{1}$ and Palma Chillón ${ }^{4}$ \\ 1 IRyS Research Group, School of Physical Education, Pontificia Universidad Católica de Valparaíso, \\ Valparaíso 2374631, Chile; carlos.cristi@pucv.cl (C.C.-M.); danica.escobar@hotmail.cl (D.E.-G.) \\ 2 BHF Glasgow Cardiovascular Research Centre, Institute of Cardiovascular and Medical Science, \\ University of Glasgow, Glasgow G128TA, UK; carlos.celis@glasgow.ac.uk \\ 3 Centro de Fisiologia y Biomecanica, Universidad Mayor, Santiago 8580000, Chile \\ 4 PROFITH "PROmoting FITness and Health through Physical Activity" Research Group, \\ Department of Physical Education and Sport, Faculty of Sports Sciences, University of Granada, \\ 18071 Granada, Spain; pchillon@ugr.es \\ * Correspondence: fernando.rodriguez@pucv.cl
}

Received: 29 August 2017; Accepted: 27 October 2017; Published: 2 November 2017

\begin{abstract}
Active commuting could contribute to increasing physical activity. The objective of this study was to characterise patterns of active commuting to and from schools in children and adolescents in Chile. A total of 453 Chilean children and adolescents aged between 10 and 18 years were included in this study. Data regarding modes of commuting and commuting distance was collected using a validated questionnaire. Commuting mode was classified as active commuting (walking and/or cycling) or non-active commuting (car, motorcycle and/or bus). Commuting distance expressed in kilometres was categorised into six subgroups ( 0 to $0.5,0.6$ to $1,1.1$ to $2,2.1$ to $3,3.1$ to 5 and $>5 \mathrm{~km}$ ). Car commuting was the main mode for children (to school 64.9\%; from school 51.2\%) and adolescents (to school 50.2\%; from school 24.7\%). Whereas public bus commuting was the main transport used by adolescents to return from school. Only $11.0 \%$ and $24.8 \%$ of children and adolescents, respectively, walk to school. The proportion of children and adolescents who engage in active commuting was lower in those covering longer distances compared to a short distance. Adolescents walked to and from school more frequently than children. These findings show that non-active commuting was the most common mode of transport and that journey distances may influence commuting modes in children and adolescents.
\end{abstract}

Keywords: active transport; youth; physical activity; adolescent

\section{Introduction}

During the last decade, physical activity levels have decreased [1] whilst sedentary-related behaviours have increased [2,3] in the Chilean adult population. These changes have been attributable to an increase in the use of motor vehicles, which drastically influence compliance with global recommendations for physical activity [4]. However, it is not only adults who have reduced their physical activity levels. Currently, $69.1 \%$ of children and adolescents do not meet the physical activity recommendations and therefore do less than one hour of moderate to vigorous physical activity (MVPA) per day [5].

Active commuting, especially in children and adolescents, has been suggested as a feasible way of increasing their overall physical levels [6]. Walking and cycling are modes of active commuting which provide numerous health benefits $[7,8]$. Public transport systems such as buses or trains also promote active commuting when compared to private transport (car commuting), as they are characterised 
by multimodal (active/non-active) transports [9]. Since commuting to and from school is conducted on a regular basis, the promotion of active commuting may be a feasible way of integrating physical activity into daily life and thus increasing the number of children and adolescents that meet the current physical activity guidelines [10].

Although there is increasing evidence regarding active commuting behaviours in children and adolescents, most of this evidence has been generated from developed countries, such as Canada, U.S., Australia and European countries [10-16]. However, there is a lack of evidence from developing countries, including Chile. Considering the rapid economic growth and fast transition towards a westernised lifestyle that Chile has experienced during the last three decades [6], it is essential to characterise and quantify the trend and patterns of active commuting to and from the school in children and adolescents. This information could inform public health authorities for the implementation and promotion of active commuting as a vehicle for tackling childhood obesity but also non-communicable diseases associated with a lack of physical activity [17]. The aim of this study was, therefore, to characterise patterns of active commuting to and from schools in children and adolescents in Chile.

\section{Material and Methods}

\subsection{Study Design and Participants}

This cross-sectional study was conducted in the urban city of Valparaiso in Chile. The sample is non-probabilistic and intentional. A total of 421 students (168 children and 253 adolescents) aged between 10 and 18 years old (equivalent to children in 5th and 7th grade and adolescents attending grades 8 to 12) were included in this study. These participants belonged to three public and two private schools from the Valparaíso region.

\subsection{Instruments}

The mode of commuting to and from school was measured using a questionnaire for children and adolescents developed by the University of Granada (Spain) through the project "PACO: pedalea y anda al colegio" (http://profith.ugr.es/paco). This questionnaire has been validated in Spanish population [18] and was the result of a systematic review of 158 studies in the scientific literature around the assessment of the mode of commuting using questionnaires [19]. Questions were selected based on their appropriateness towards the objective of the study. Students completed this questionnaire with assistance from their teacher. The questionaire included closed-ended questions with multiple answers. The usual mode of commuting to and from school was categorised into "active" commuting (walking and cycling) and non-active commuting (car, motorcycle, or bus). For commuting distance from home to their school participants could choose any of the following options: 0 to $0.5 \mathrm{~km}$, 0.6 to $1 \mathrm{~km}, 1.1$ to $2 \mathrm{~km}, 2.1$ to $3 \mathrm{~km}, 3.1$ to $5 \mathrm{~km}$ and $>5 \mathrm{~km}$. The reliability of the questionaire was measured in a sub-sample of 219 Chilean children and adolescents by applying the same questionnaire on two different occasions 7 days apart. The usual mode to and from school shows a high reliability (Kappa $>0.85$ ), whereas commuting distance shows a moderate reliability (Kappa $>0.69$ ).

\subsection{Procedure}

The questionnaire was completed between April and June 2017. The students completed the questionnaires in 15 to $30 \mathrm{~min}$ with the assistance of their school teachers.

\subsection{Ethical Aspects}

Prior to data collection, parents and students were informed about the characteristics of the questionnaire, the study purpose, and the confidentiality of the results. All questionnaires were answered voluntarily and with parental consent. Therefore, all participants gave informed consent for participating in the study, following the rules, with the study approved by Ethics Committee of the Pontificia Universidad Católica de Valparaíso (code: CCF02052017) and the 2004 Helsinky statement. 


\subsection{Data Analysis}

The results are presented as means and standard deviations for continuous variables and as a prevalence rate for categorical variables. For analysis purposes, the sample was stratified into groups by sex and age for both children and adolescents. Differences in commuting mode between gender (boys vs. girls), age (children vs. adolescents) and commuting route (to school vs. from school) were assessed using the Chi-square test. Differences for commuting distance by age and commuting mode were also investigated using Chi-square test. All statistical analyses were performed using the statistical program SPSS ${ }^{\circledR}$ version 21 (IBM, New York, NY, USA). A $p$-value $(<0.05)$ was set as significant in all analyses.

\section{Results}

Table 1 presents the characteristics of the school children participating in the study including gender, age and type of school (Private or Public).

Table 1. Descriptive sociodemographic data of the participants.

\begin{tabular}{ccccccc}
\hline \multirow{2}{*}{ Characteristics } & \multicolumn{2}{c}{ Overall } & \multicolumn{2}{c}{ Children } & \multicolumn{2}{c}{ Adolescents } \\
\cline { 2 - 7 } & $n$ & $\mathbf{( \% )}$ & $\boldsymbol{n}$ & $\mathbf{( \% )}$ & $\boldsymbol{n}$ & $\mathbf{( \% )}$ \\
\hline All & 453 & $(100)$ & 171 & $(37.7)$ & 282 & $(60.6)$ \\
\hline Gender & & & & & & \\
\hline Male & 228 & $(50.3)$ & 86 & $(50.3)$ & 142 & $(50.4)$ \\
Female & 225 & $(49.7)$ & 85 & $(49.7)$ & 140 & $(49.6)$ \\
\hline Type of school & & & & & & \\
\hline Private School & 258 & $(57.0)$ & 85 & $(49.7)$ & 173 & $(61.3)$ \\
Public School & 195 & $(43.0)$ & 91 & $(53.2)$ & 104 & $(36.9)$ \\
Age (mean + SD) & 12.7 & \pm 2.0 & 10.6 & \pm 0.6 & 13,9 & \pm 1.5 \\
\hline
\end{tabular}

The modes of commuting to and from school for both children and adolescents are shown in Table 2. The proportion of children and adolescents who reported walking to and from the school was $11 \%$ and $24.8 \%$, respectively. In children, car commuting was the main commuting mode reported (64.9\% going to school and $51.2 \%$ returning from school), whereas for adolescents $50.2 \%$ reported commuting to school by car but $37.5 \%$ reported using the bus to return from school.

Table 2. Mode of commuting to and from school by sex in children and adolescents.

\begin{tabular}{|c|c|c|c|c|c|c|c|}
\hline \multirow[b]{2}{*}{ To School } & \multicolumn{3}{|c|}{ Children } & \multicolumn{3}{|c|}{ Adolescents } & \\
\hline & Overall & Boys & Girls & Overall & Boys & Girls & \\
\hline & $n(\%)$ & $n(\%)$ & $n(\%)$ & $n(\%)$ & $n(\%)$ & $n(\%)$ & $p$-Value \\
\hline \multicolumn{8}{|c|}{ Active commuting } \\
\hline Walking & $15(8.9)$ & $9(10.7)$ & $6(7.1)$ & $59(23.3)$ & $31(25.4)$ & $28(21.4)$ & $<0.001$ \\
\hline Bicycle & $0(0.0)$ & $0(0.0)$ & $0(0.0)$ & $0(0.0)$ & $0(0.0)$ & $0(0.0)$ & - \\
\hline \multicolumn{8}{|c|}{ Non-active commuting } \\
\hline Car & $109(64.9)$ & $54(64.3)$ & 55 (65.5) & $127(50.2)$ & $54(44.3)$ & 73 (55.7) & 0.003 \\
\hline School Bus & $12(7.1)$ & $8(9.5)$ & $4(4.8)$ & $6(2.4)$ & $4(3.3)$ & $2(1.5)$ & $<0.001$ \\
\hline Public Bus & $4(2.4)$ & $3(3.6)$ & $1(1.2)$ & $57(22.5)$ & $33(27.0)$ & $24(18.3)$ & 0.018 \\
\hline Metro/Train & $3(1.8)$ & $2(2.4)$ & $1.2(1)$ & $2(0.8)$ & $0(0.0)$ & $2(1.5)$ & 0.356 \\
\hline Motorcycle & $25(14.9)$ & $8(9.5)$ & $17(20.2)$ & $2(0.8)$ & $0(0.0)$ & $2(1.5)$ & $<0.001$ \\
\hline
\end{tabular}


Table 2. Cont.

\begin{tabular}{|c|c|c|c|c|c|c|c|}
\hline \multirow[b]{2}{*}{ From School } & \multicolumn{3}{|c|}{ Children } & \multicolumn{3}{|c|}{ Adolescents } & \multirow[b]{3}{*}{$p$-Value } \\
\hline & Overall & Boys & Girls & Overall & Boys & Girls & \\
\hline & $n(\%)$ & $n(\%)$ & $n(\%)$ & $n(\%)$ & $n(\%)$ & $n(\%)$ & \\
\hline \multicolumn{8}{|c|}{ Active commuting } \\
\hline Walking & $23(13.1)$ & 14 (15.7) & $9(10.7)$ & $81(32.2)$ & $44(36.4)$ & 37 (28.5) & $<0.001$ \\
\hline Bicycle & $0(0.0)$ & $0(0.0)$ & $0(0.0)$ & $0(0.0)$ & $0(0.0)$ & $0(0.0)$ & - \\
\hline \multicolumn{8}{|c|}{ Non-active commuting } \\
\hline Car & $86(51.2)$ & 45 (53.6) & $41(48.8)$ & $62(24.7)$ & $28(23.1)$ & $34(26.2)$ & $<0.001$ \\
\hline School Bus & $25(14.9)$ & $9(10.7)$ & $16(19.0)$ & $8(3.2)$ & $1(0.8)$ & $7(5.4)$ & $<0.001$ \\
\hline Public Bus & $6(3.6)$ & $4(4.8)$ & $2(2.4)$ & $94(37.5)$ & $48(39.7)$ & $46(35.4)$ & $<0.001$ \\
\hline Metro/Train & $2(1.2)$ & $2(2.4)$ & $0(0.0)$ & $4(1.6)$ & $0(0.0)$ & $4(3.1)$ & 0.734 \\
\hline Motorcycle & $26(15.5)$ & 10 (11.9) & $16(19.0)$ & $1(0.4)$ & $0(0.0)$ & $1(0.8)$ & $<0.001$ \\
\hline
\end{tabular}

Chi square test $(p<0.05)$ was used to assess diferecnes in commuting modes by children and adolescents. Significant differences were set at $p<0.05$.

The modes of commuting between children and adolescents were statistically different, except for the metro or train commuting. Adolescents reported walking more frequently than children $(p<0.001)$. They also reported a lower use of car commuting and a higher use of public transport when compared to children. Interestingly, children commuted more by motorcycle (in the company of their parents) than adolescents $(p<0.001)$, while neither children nor adolescents used bicycles as a prominent mode of commuting to school.

Differences between the modes of commuting by route of commuting (to and from school) are shown in Figure 1. Car commuting was the main commuting mode used for both children and adolescents to travel from home to the school. However, car, public bus and walking were the main commuting modes used to return from school in adolescents. Car commuting remains the main commuting mode for returning from school in children.

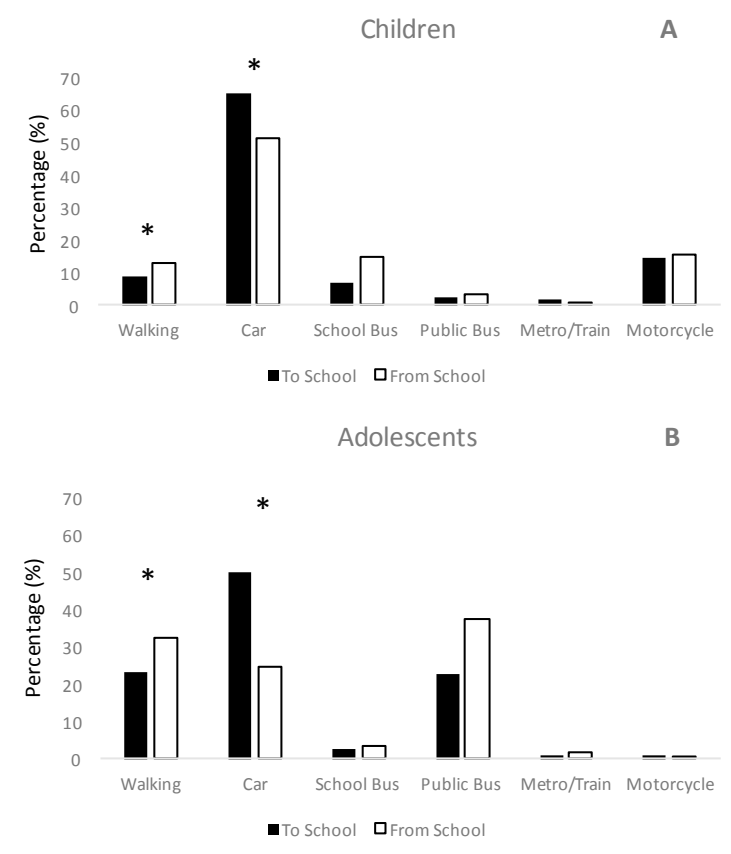

Figure 1. Comparison of the modes of commuting to and from school, in children (A) and adolescents (B). * $p<0.05$ value between "To school" and "From school" in children and adolescents by car and walking. 
The commuting distances from home to school in children and adolescents are shown in Table 3. Commuting distances ranging from 0 to $5 \mathrm{~km}$ did not show any significant differences between children and adolescents. However, commuting distances greater than $5 \mathrm{~km}$ are significantly higher for adolescents than for children.

Table 3. Distances from home to school in children and adolescents.

\begin{tabular}{cccccc}
\hline \multirow{2}{*}{ Distance } & \multicolumn{2}{c}{ Children } & \multicolumn{3}{c}{ Adolescents } \\
\cline { 2 - 6 } & $\%$ & $(\boldsymbol{n})$ & $\%$ & $(\boldsymbol{n})$ & $\boldsymbol{p}$-Value \\
\hline $0-0.5 \mathrm{~km}$ & $13.1 \%$ & $(22)$ & $16.1 \%$ & $(41)$ & 0.711 \\
$0.6-1 \mathrm{~km}$ & $13.7 \%$ & $(23)$ & $14.5 \%$ & $(37)$ & 0.056 \\
$1.1-2 \mathrm{~km}$ & $14.3 \%$ & $(24)$ & $13.3 \%$ & $(34)$ & 0.078 \\
$2.1-3 \mathrm{~km}$ & $9.5 \%$ & $(16)$ & $8.2 \%$ & $(21)$ & 0.211 \\
$3.1-5 \mathrm{~km}$ & $13.1 \%$ & $(22)$ & $10.6 \%$ & $(27)$ & 0.621 \\
$>5 \mathrm{~km}$ & $36.3 \%$ & $(61)$ & $37.3 \%$ & $(95)$ & 0.039
\end{tabular}

Data presented as \% (number of individuals). Significant differences were accepted at $p<0.05$.

Figure 2 shows the percentage of children by commuting distance and commuting mode. The results show that active commuters are more likely to commute shorter distances $(<1 \mathrm{~km})$, whereas the proportion of non-active commuters increases for middle and long distances $(>1 \mathrm{~km})$ in both children and adolescents.
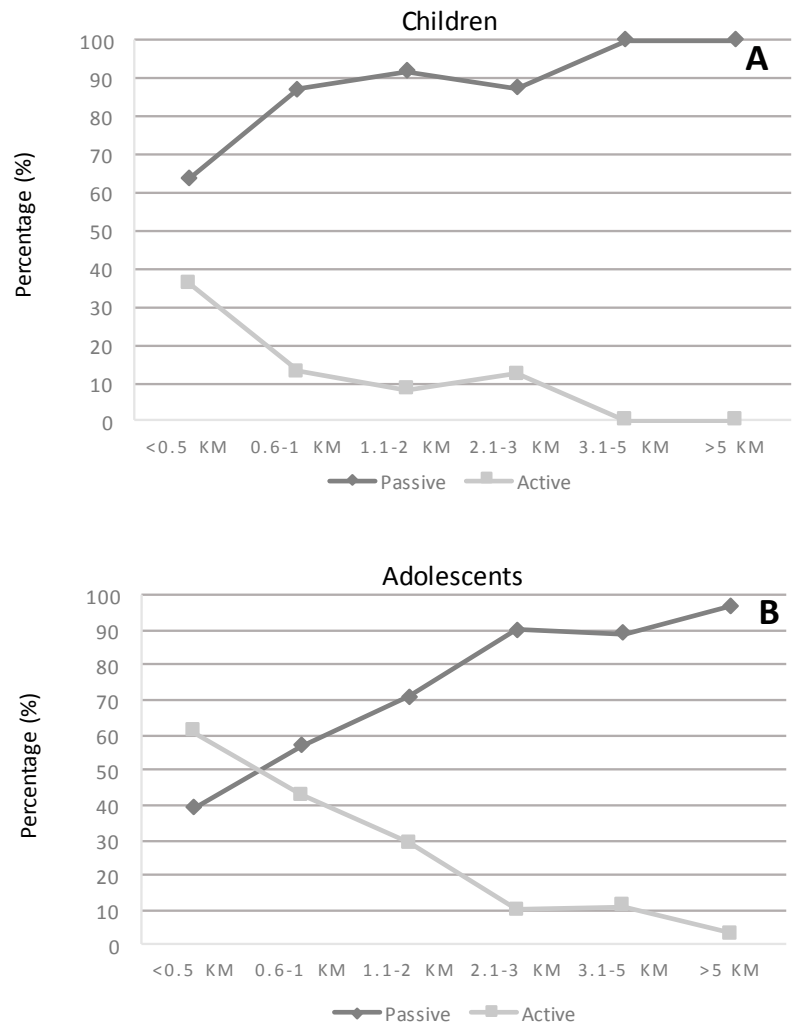

Figure 2. Distances from home to school according to active or non-active modes of commuting in children (A) and adolescents (B).

\section{Discussion}

The main findings of this study indicate that car commuting is the most popular commuting mode in both children (to school $64.9 \%$; from school 51.2\%) and adolescents (to school 50.2\%; from school 24.7\%). Most adolescents, however, used the public bus to return from school. Interestingly, 
walking was the only active mode used, with no participants reporting cycling to or from school. The proportion of walking commuters is higher in adolescents than in children. As expected, the percentage of both children and adolescents who walk to school was higher for those who commute short distances. It is worthy of note that this is the first study addressing patterns of different commuting modes in young Chilean students, which reinforces the need for more research on this subject.

\subsection{Patterns of Mode of Commuting}

Less than $10 \%$ of children and around $25 \%$ of adolescents reported commuting by walking in the present study. These results are lower than those reported by other developed countries such as Spain where $62.4 \%$ of schoolchildren walked or cycled to school [17], or Belgium where $65.2 \%$ of girls and $65.5 \%$ of boys used active commuting to school [16]. However, adolescents from North America showed a similar proportion of active commuting to those observed in our study [20,21], $15 \%$ of 13-year-old Canadian students walked to school [19], and only $8 \%$ of adolescents between the ages of 14 and 17 in the USA walked to school once a week [21].

Interestingly, none of the participants included in this study reported cycling to or from school. Similarly, in Spain, only $0.5 \%$ of students cycle to school [17]. However, in Belgium, $44.4 \%$ of students used a bicycle as a means of transport [16]. In the Netherlands, $31.8 \%$ of school children cycle to school [22]. Cultural and road safety differences within these countries could explain the differences observed within Chile, Belgium and The Netherlands. These countries have a large tradition of cycling, not only in students, but in the whole population [14,22]. In addition, it is important to bear in mind the geographical context of the region of Valparaíso, where the Chilean participants came from. Valparaíso has important inconveniences such as long distances from home to school and the different geography between the coast and the hills inland. Moreover, the scarce availability of bicycle paths (only $2 \mathrm{~km}$ ) does not favour the use of this mode of transport. Other cities in Chile, such as Rancagua, Curicó, and Talca, show a higher use of bicycles in daily commuting ( $4 \%, 12 \%$ and $8 \%$, respectively) [23]. These cities are located on flat landscapes and are characterised by being geographically more accessible.

Our results show that car commuting is the most popular mode of commuting for both children and adolescents. However, adolescents reported using public bus as the second most common mode of commuting from school to home. These data show the increasing level of independent mobility that adolescents have when compared to children. In addition, the use of public transport also implies some form of active commuting [24,25], and it is more highly recommended for young people than private transport from a health and autonomous point of view. A study conducted in the US showed that children undertake an average of 19 min physical activity to walk from home or school to the public transport stops or stations [8].

\subsection{Distance from Home to School}

This study revealed that more than $35 \%$ of children and adolescents live more than $5 \mathrm{~km}$ away from school and only $20 \%$ of children live less than $0.5 \mathrm{~km}$ away. These findings may suggest that long distances between home and school is one of the main limitations in the promotion of active commuting behaviours in children and adolescents. An Australian study [26] reported that the greater the distance between home and school, the lower the percentage of school children who actively commute every day. In addition, this study pointed out that school children who live less than $750 \mathrm{~m}$ away from school are more active. This data coincides with the adolescent group in the present study. It has been established that school children living less than $800 \mathrm{~m}$ from school, are 5 times more likely to walk [27]. A Spanish study identified $800 \mathrm{~m}$ as a walkable distance for children going to school [28]. In addition, other researchers established differences with cut off points at $875 \mathrm{~m}$ in children and $1.35 \mathrm{~km}$ in adolescents [29]. This means that the threshold distance for active commuting increases 
with age. For example, Chillón et al. [30], established a threshold distance among English young people at 1.4, 1.6 and $3.0 \mathrm{~km}$ for students aged 10, 11 and 14 years old, respectively.

Given that schools are far from residential areas, developing catchment areas policies to reduce distances and promote active commuting could bring the Chilean context closer to that of other countries in Europe. These results provide several insights that should be further analysed and improved on within the Chilean society. The main issue is that parents in Chile travel more than an hour on a daily basis to take their children to private schools-which are considered to be more qualified than the public schools located closer to family homes. This trend negatively affects the promotion of active commuting to school, since longer distances often force families to use their cars. It would be helpful to promote active commuting by improving governmental policies that ensure safety and reduce barriers to active commuting. Furthermore, it may help society to tackle the high inactivity and alarming childhood and adolescent obesity rate in Chile.

\subsection{Strengths and Limitations}

The main strengths of this study are that this is the first study to describe the modes of commuting in Chilean children and adolescents, and that it provides reliable data originating from the questionnaire. Limitations are the low number of total participants, the low heterogeneity of the Chilean cities included in the sample, and the self-reported distance from home to school.

\section{Conclusions}

The most common mode of commuting in children and adolescents from Valparaiso is the car, and the rate of walking was lower than in other European and North American countries. This study shows higher independent mobility in adolescents (walking and public transportation) when compared to children. In addition, the long distance from home to school appears to be a main barrier in the promotion of active modes of commuting among the Chilean school children. These results provide unique information on active commuting patterns in school children which could be used to inform public health authorities for the promotion and facilitation of active commuting in children and adolescents. This, in turn, could have important implications for health during adulthood.

Acknowledgments: To the teachers and students of the participating schools, the CONICYT PAI-MEC programme (MEC 80150030), the Academic Incentive Programs from the Research Department of the Pontificia Universidad Católica de Valparaíso, Valparaiso-Chile and funding from the University of Granada 2016 (Unit of Excellence on Exercise and Health-UCEES). We are grateful to Carmen Sainz-Quinn for assistance with the English language.

Author Contributions: Study conception and design: Fernando Rodríguez-Rodríguez; Palma Chillon. Acquisition of data: Danica Escobar-Gómez; Fernando Rodríguez-Rodríguez. Analysis and interpretation of data: Fernando Rodríguez-Rodríguez; Danica Escobar-Gómez; Palma Chillon. Drafting of manuscript: Fernando Rodríguez-Rodríguez; Carlos Cristi-Montero; Carlos Celis-Morales; Danica Escobar-Gómez; Palma Chillon. Critical revision: Fernando Rodríguez-Rodríguez; Carlos Cristi-Montero; Carlos Celis-Morales; Danica Escobar-Gómez; Palma Chillón.

Conflicts of Interest: The authors declare no conflict of interest.

\section{References}

1. World Health Organization (WHO). Recomendaciones Mundiales Sobre Actividad Física Para la Salud; World Health Organization: Geneva, Switherland, 2010.

2. Pate, R.R.; O'Neill, J.R.; Lobelo, F. The evolving definition of "sedentary". Exerc. Sport. Sci. Rev. 2008, 36, 173-178. [CrossRef] [PubMed]

3. Owen, N.; Healy, G.N.; Matthews, C.E.; Dunstan, D.W. Too much sitting: The population-health science of sedentary behavior. Exerc. Sport. Sci. Rev. 2010, 36, 105-133. [CrossRef] [PubMed]

4. Granich, J.; Rosenberg, M.; Knuiman, M.W.; Timperio, A. Individual, Social, and Physical Environment Factors Associated With Electronic Media Use among Children: Sedentary Behavior at Home. J. Phys. Act. Health 2011, 8, 613-625. [CrossRef] [PubMed] 
5. Wang, H.; Blanco, E.; Algarín, C.; Peirano, P.; Burrows, R.; Reyes, M.; Wing, D.; Godino, J.; Gahagan, S. Weight Status and Physical Activity: Combined Influence on Cardiometabolic Risk Factors among Adolescents, Santiago, Chile. Glob. Pediatr. Health 2016. [CrossRef] [PubMed]

6. Audrey, S.; Procter, S.; Cooper, A.R. The contribution of walking to work to adult physical activity levels: A cross sectional study. Int. J. Behav. Nutr. Phys. Act. 2014, 11. [CrossRef] [PubMed]

7. Saunders, L.E.; Green, J.M.; Petticrew, M.P.; Steinbach, R.; Roberts, H. What Are the Health Benefits of Active Travel? A Systematic Review of Trials and Cohort Studies. PLoS ONE 2013. [CrossRef] [PubMed]

8. Celis-Morales, C.A.; Lyall, D.M.; Welsh, P.; Anderson, J.; Steell, L.; Guo, Y.; Maldonado, R.; Mackay, D.F.; Pell, J.P.; Sattar, N.; et al. Association between active commuting and incident cardiovascular disease, cancer, and mortality: Prospective cohort study. BMJ 2017. [CrossRef] [PubMed]

9. Besser, L.M.; Dannenberg, A.L. Walking to public transit: Steps to help meet physical activity recommendations. Am. J. Prev. Med. 2005, 29, 273-280. [CrossRef] [PubMed]

10. Faulkner, G.E.J.; Buliung, R.N.; Flora, P.K.; Fusco, C. Active school transport, physical activity levels and bodyweight of children and youth: A systematic review. Prev. Med. 2009, 48, 3-8. [CrossRef] [PubMed]

11. McDonald, N.C.; Steiner, R.L.; Lee, C.; Rhoulac Smith, T.; Zhu, X.; Yang, Y. Impact of the safe routes to school program on walking and bicycling. J. Am. Plan. Assoc. 2014, 80, 153-167. [CrossRef]

12. Buliung, R.N.; Mitra, R.; Faulkner, G. Active school transportation in the Greater Toronto Area, Canada: An exploration of trends in space and time (1986-2006). Prev. Med. 2009, 48, 507-512. [CrossRef] [PubMed]

13. Chillón, P.; Martínez-Gómez, D.; Ortega, F.B.; Pérez-López, I.J.; Díaz, L.E.; Veses, A.M.; Veiga, O.L.; Marcos, A.; Delgado-Fernández, M. Six-year trend in active commuting to school in Spanish adolescents. Int. J. Behav. Med. 2013, 20, 529-537. [CrossRef] [PubMed]

14. Sun, Y.; Liu, Y.; Tao, F.B. Associations between active commuting to school, body fat, and mental well-being: Population-based, cross-sectional study in China. J. Adolesc. Health 2015, 57, 679-685. [CrossRef] [PubMed]

15. Bringolf-Isler, B.; Grize, L.; Mäder, U.; Ruch, N.; Sennhauser, F.H.; Braun-Fahrländer, C. Personal and environmental factors associated with active commuting to school in Switzerland. Prev. Med. 2008, 46, 67-73. [CrossRef] [PubMed]

16. Vanwolleghem, G.; Van Dyck, D.; De Meester, F.; De Bourdeaudhuij, I.; Cardon, G.; Gheysen, F. Which socio-ecological factor sassociate with a switch to orma intenance of active and passive transport during the transition from primary to secondary school? PLoS ONE 2016, 11, e0156531. [CrossRef] [PubMed]

17. Rodríguez-López, C.; Villa-González, E.; Pérez-López, I.J.; Delgado-Fernández, M.; Ruiz, J.R.; Chillón, P. Family factors influence active commuting to school in spanish children. Nutr. Hosp. 2013, 28, 756-763. [PubMed]

18. Chillón, P.; Herrador-Colmenero, M.; Migueles, J.H.; Cabanas-Sánchez, V.; Fernández-Santos, J.R.; Veiga, O.L.; Castro-Piñero, J. Convervent validation of a questionnaire to assess the mode and frequency of commuting to and from school. Scand. J. Public Health. 2017, 45, 612-620. [CrossRef]

19. Herrador-Colmenero, M.; Pérez-García, M.; Ruiz, J.R.; Chillón, P. Assessing modes and frequency of commuting to school in youngsters: A systematic review. Pediatr. Exerc. Sci. 2014, 26, 291-341. [CrossRef] [PubMed]

20. Pabayo, R.; Gauvin, L. Proportions of students who use various modes of transportation to and from school in a representative population-based sample of children and adolescents, 1999. Prev. Med. 2008, 46, 63-66. [CrossRef] [PubMed]

21. Evenson, K.R.; Huston, S.L.; McMillen, B.J.; Bors, P.; Ward, D.S. State wide prevalence and correlates of walking and bicycling to school. Arch. Pediatr. Adolesc. Med. 2003, 157, 887-892. [CrossRef] [PubMed]

22. Aarts, M.J.; Mathijssen, J.J.; van Oers, J.A.; Schuit, A.J. Associations between environmental characteristics and active commuting to school among children: A cross-sectional study. Int. J. Behav. Med. 2013, 20, 538-555. [CrossRef] [PubMed]

23. MINVU. Vialidad Ciclo-Inclusiva; Ministerio de Vivienda y Urbanismo: Santiago, Chile, 2015.

24. Djurhuus, S.; Hansen, H.S.; Aadahl, M.; Glümer, C. The association between access to public transportation and self-reported active commuting. Int. J. Environ. Res. Public Health 2014, 11, 12632-12651. [CrossRef] [PubMed]

25. Bopp, M.; Bopp, C.; Schuchert, M. Active Transportation to and on Campus is Associated with Objectively Measured Fitness Outcomes among College Students. J. Phys. Act. Health 2015, 12, 418-423. [CrossRef] [PubMed] 
26. Merom, D.; Tudor-Locke, C.; Bauman, A.; Rissel, C. Active commuting to school among NSW primary schoolchildren: Implications for public health. Health Place 2006, 12, 678-687. [CrossRef] [PubMed]

27. Timperio, A.; Ball, K.; Salmon, J.; Roberts, R.; Giles-Corti, B.; Simmons, D.; Baur, L.; Crawford, D. Personal, family, social, and environmental correlates of active commuting to school. Am. J. Prev. Med. 2006, 30, 45-51. [CrossRef] [PubMed]

28. Gutiérrez-Zornoza, M.; Sánchez-López, M.; García-Hermoso, A.; González-García, A.; Chillón, P.; Martínez-Vizcaíno, V. Active Commuting to School, Weight Status, and Cardiometabolic Risk in Children From Rural Areas The Cuenca Study. Health Educ. Behav. 2014, 42, 231-239. [CrossRef] [PubMed]

29. Rodríguez-López, C.; Salas-Fariña, Z.M.; Villa-González, E.; Borges-Cosic, M.; Herrador-Colmenero, M.; Medina-Casaubón, J.; Ortega, F.; Chillón, P. The threshold distance associated with walking from home to school. Health Educ. Behav. 2017. [CrossRef] [PubMed]

30. Chillón, P.; Panter, J.; Corder, K.; Jones, A.P.; Van Sluijs, E.M. A longitudinal study of the distance that young people walk to school. Health Place 2015, 31, 133-137. [CrossRef] [PubMed]

(C) 2017 by the authors. Licensee MDPI, Basel, Switzerland. This article is an open access article distributed under the terms and conditions of the Creative Commons Attribution (CC BY) license (http:/ / creativecommons.org/licenses/by/4.0/). 